\title{
The regulation, assessment, and management of medical devices in Mexico: How do they shape the quality of delivered healthcare?
}

Myriam Lingg ${ }^{1,2^{*}}$ (D) Anahi Dreser Mansilla ${ }^{3}$, Luis Durán-Arenas ${ }^{4}$ and Kaspar Wyss ${ }^{1,2}$

\begin{abstract}
Background: Policies for health technologies such as medical devices are essential and contribute to improved quality of healthcare. The regulation, assessment, and management represent important functions of medical devices. Insufficiently developed interactions between these functions impact the quality of delivered healthcare. To date studies lack to analyse these functions in a broad way. The aim of this study is to analyse the regulation, assessment, and management of orthopaedic medical devices in Mexico and how they shape healthcare.

Methods: This qualitative study included 42 stakeholders involved directly or indirectly in the regulation, assessment, or management for orthopaedic medical devices in Mexico.

Results: The fragmentation of responsibilities for medical device functions may be a central aspect of our findings concerning challenges reported by interviewees. Strengthening technovigilance based on improved reporting across health care institutions emerged as pathway to improve medical device regulation. With regard to improving the medical device assessment, a comprehensive update of the standard list represents a relevant opportunity. Integrating advanced quality attributes into procurement processes regarding decision-making, purchasing strategy, and procurement agent is needed to fostering the management.

Conclusions: This study provides a broad analysis of medical device functions within a health system and highlights in this specific context how improvements might be achieved. It addresses a broad range of interest groups represented by policy makers, health service providers, managers and administrators of healthcare facilities, and doctors with an interest in health technologies. In this paper we highlight important themes that influence outputs and outcomes of the regulation, assessment, and management and discuss strategies in fostering these areas. To date, the regulation, assessment, and management of medical devices are rarely analysed in a broad way, even though these functions importantly contribute to the successful implementation of health technology policies. The quality of delivered healthcare is influenced by the performance between and within these functions. In Mexico, little discussion has been raised on challenges of the regulation, assessment, and management of medical devices. Changes to current processes and practices can improve outputs and outcomes of these functions and positively influence the quality of delivered healthcare. Stakeholder involvement and commitment is essential to this.
\end{abstract}

Keywords: Assessment, Health technology, Management, Medical device, Mexico, Regulation

\footnotetext{
* Correspondence: myriam.lingg@yahoo.de

${ }^{1}$ Swiss Tropical and Public Health Institute, Swiss Centre for International Health, Socinstrasse, 574051 Basel, Switzerland

2University of Basel, Petersplatz 1, 4003 Basel, Switzerland

Full list of author information is available at the end of the article
} 


\section{Background}

Policies for health technologies such as medical devices are essential to assure equitable access to high quality and affordable devices and their appropriate use and thus contributing to improved quality of care [1]. The World Health Organization (WHO) emphasizes the importance of developing and implementing health technology policies within the context of a national health plan. WHO indicated that $34 \%$ of 145 countries have a health technology national policy in place that is part of the national health programme [2]. Mexico is one of these countries and has established several government agencies (Table 1) and defined regulations that support policies for health technologies. This is key to organize and support, and strengthen important functions for medical devices. These functions are the regulation, assessment, and management of medical devices and compose important areas of the Medical Device Life-Cycle (MDLC) (Table 2) and support health care delivery at different organizational levels within the health system.

Besides the development and implementation of health technology policies, WHO emphasizes the importance of the commitment for, and realization of a continuous improvement plan within and between the areas of the MDLC in order to strengthen the implementation of national health technology policies and to contribute to improved health [1]. This can be achieved when necessary interactions between these areas are established because of their interdependence. To date, there are indications of questions regarding different attributes of the MDLC for orthopaedic high-risk medical devices (HRMDs) in Mexico and their influence on clinical practice and thus on the delivered quality of health care [3-7]. HRMDs are implanted in the human body (such as a knee joint implant) and are therefore recommended subject to the highest level of pre-market and postmarket regulation [8]. To date, little is known how these attributes affect outputs and outcomes of the MDLC and its meaning for quality of health care. The articles 83, 179 and 180 of the current Medical Device Regulation of Mexico indicate that there are no specific regulations for HRMDs differentiating them from lower risk medical devices.

The Mexican health system is a complex system with multiple actors encompassing a public private mix of hospital providers [9]. The national health care system is decentralized with planning, management, and regulatory authority shared at the federal and state-level $[10,11]$. In Mexico, the different sub-systems of health care (social security and state-level health care systems (SESA)) are disconnected and the level of health care and outcomes between these sub-systems varies [12]. This leads to a fragmentation of responsibilities with regard to the MDLC areas, which might affect the ability of policymakers to comprehensively oversee the MDLC in Mexico.

The aim of the present study is to analyse challenges of the regulation, assessment, and management of orthopaedic medical devices in Mexico and their impact on outputs and outcomes of the MDLC. Further, we discuss possible ways forward in fostering the regulation, assessment, and management and their influence on the quality of delivered health care.

\section{Methods}

Our research approach is based on a working framework (Fig. 1), which is guided by two considerations: (i) MDLC represents key functions for medical devices and as a whole it is a functional system contributing to improved health, and (ii) important stakeholders related to the MDLC exert their influence at the macro level (regulation and policy mechanism), meso level (public health care institutions and care provider facilities), and micro level (healthcare professional and patient). The framework guided the data collection and analysis. This research is part of a larger study to investigate the relation between the regulation, assessment and management of orthopaedic HRMDs in Mexico and their impact on clinical procedures.

\section{Study population and recruitment}

The study was done in Mexico. We identified and recruited participants for interviews by searching listings from the governmental offices, public sector, orthopaedic specialists (public and private sector), organisations, medical device supplier. We used a maximum variation sampling [13] to recruit key stakeholder based on three sample criteria: (1) stakeholders influencing MDLC areas; [14] stakeholders influencing between MDLC areas; and [14] stakeholders that have potential to influence MDLC areas in the future.

\section{Data collection}

In total 42 interviews were conducted between April and May 2016 by the principal investigator and a research assistant. The principal investigator and a research assistant conducted interviews in Spanish. We used a file-naming system and anonymized interviewees by generating a list of archival numbers. We used faceto-face interviews $(n=39)$ and phone interviews $(n=3)$ (Table 3). All interviews were audio recorded, transcribed, and reviewed again by the principal investigator with the exception of one interview owing to employer requirements and we used an interview protocol. The interview guide (Additional file 1) was previously validated among a small group of persons familiar with medical device regulation, assessment, and management. 
Table 1 Principle actors involved in MDLC areas

\begin{tabular}{|c|c|c|c|c|}
\hline \multirow[t]{2}{*}{ Stakeholders } & \multirow[t]{2}{*}{ Main responsibility } & \multicolumn{3}{|c|}{ Relative importance for MDLC areas } \\
\hline & & Tehno-vigilance & Assessment & Purchasing \\
\hline $\begin{array}{l}\text { Sub-secretariat for Health System } \\
\text { Integration and Development, SIDSS }\end{array}$ & $\begin{array}{l}\text { - Government agency whose mission is to propose } \\
\text { to the MoH national policies that improve the quality } \\
\text { of social health services; issues the Mexican Official } \\
\text { Norms (NOM) }\end{array}$ & ++ & +++ & $++(+)$ \\
\hline $\begin{array}{l}\text { Departments of Sub-secretariat for } \\
\text { Health System Integration and } \\
\text { Development }\end{array}$ & $\begin{array}{l}\text { - General directorate of health planning and development, } \\
\text { DGPD: Governmental organization and unit under the } \\
\text { authority of the SIDSS whose mission is to steer the } \\
\text { strengthening of health services among policy makers, } \\
\text { and giving guidance to improve health services sustainable } \\
\text { and cultural based on populations' needs. } \\
\text { - General directorate of quality and education, DGCE: } \\
\text { Governmental organization and unit under the authority } \\
\text { of the SIDSS whose mission is to ensure that the quality } \\
\text { and safety of health services, including human resources } \\
\text { of the health sector and the regulatory environment of } \\
\text { social health supplies is aligned with national policies. }\end{array}$ & ++ & +++ & $++(+)$ \\
\hline General Council of Health, CSG & $\begin{array}{l}\text { - Sanitary authority directly accountable to the President } \\
\text { - Council whose mission it is to strengthen the governance } \\
\text { and the articulation of the National System of Health. } \\
\text { Founded: } 1917 \\
\text { - Publishes the standard list of Health Supplies } \\
\text { - Holds the Inter-institutional Commission of the standard } \\
\text { list for Health Supplies whose mission is to manage the } \\
\text { approved technologies in the standard list for Health Supplies } \\
\text { - Auditing of hospitals with regards to quality standards } \\
\text { (certification process) }\end{array}$ & ++ & $++(+)$ & + \\
\hline $\begin{array}{l}\text { Federal Commission for the } \\
\text { Protection against Sanitary Risks, } \\
\text { COFEPRIS }\end{array}$ & $\begin{array}{l}\text { - Decentralized organ of the MoH whose mission is to } \\
\text { protect the population against medical risks derived from } \\
\text { the introduction of new medical drugs, medical devices } \\
\text { and other health inputs. Founded: } 2002 \\
\text { - Sanitary Authorization Commission whose mission is the } \\
\text { market approval of medical products and technologies. } \\
\text { - Technovigilance department whose mission is to implement } \\
\text { and realize post-market surveillance. } \\
\text { - Support function of "Sanitary Authorization Commission" } \\
\text { whose mission is to provide technovigilance reports for } \\
\text { the renovation of market approval. }\end{array}$ & +++ & ++ & + \\
\hline $\begin{array}{l}\text { National Centre for Health } \\
\text { Technology Excellence, CENETEC }\end{array}$ & $\begin{array}{l}\text { - Governmental organization and unit under the scope of } \\
\text { the SIDSS whose mission is to contribute to the development } \\
\text { and governance of the National Health System in Mexico } \\
\text { based on: Health Technology Assessments, Supervision of } \\
\text { medical equipment, Telemedicine, Clinical guidelines. } \\
\text { Founded: } 2004 \\
\text { - WHO collaborating centre. }\end{array}$ & ++ & $++(+)$ & $++(+)$ \\
\hline \multirow[t]{2}{*}{$\begin{array}{l}\text { Sub-systems: Centralized and } \\
\text { decentralized health services }\end{array}$} & $\begin{array}{l}\text { - Functionary with national responsibilities within the } \\
\text { sub-system; director of healthcare facility; procurement } \\
\text { agent }\end{array}$ & +++ & $++(+)$ & +++ \\
\hline & $\begin{array}{l}\text { - Functionary with local responsibility: Head of orthopaedic } \\
\text { department }\end{array}$ & - & $+(+)$ & ++ \\
\hline
\end{tabular}

+++ strong relation ++ moderate relation + low relation - no relation

\section{Data analysis}

To assess views of stakeholders on challenges of and possible ways forward in fostering the MDLC areas, we thematically analysed the transcripts [15]. MAXQDA software (version 11, VERBI GmbH) was used to aid data management. To describe the views of stakeholders regarding challenges, first, we closely read each transcript. Second, we deductively coded one-third of the transcripts based on the themes of our conceptual framework and inductively coded for new themes. Third, we clustered codes into categories, revised the final list of codes and categories. Fourth, we systematically applied coding to all transcripts and drew on important themes. The principal investigator analysed all primary data alone, which implies a limitation of validity check. To integrate the views of stakeholders regarding possible ways forward in fostering MDLC areas into the discussion of the present study we analysed them in the 
Table 2 Important outputs and outcomes of the MDLC areas

\begin{tabular}{llll}
\hline Areas & Description & Outputs & Outcomes \\
\hline Regulation & $\begin{array}{l}\text { Safety and efficacy are in the focus of this phase to } \\
\text { aim population safety. Key elements are performing } \\
\text { testing, safety assessment \& post-market reporting } \\
\text { using criteria of safety and quality standards. }\end{array}$ & Mandatory compliance & Assuring minimal standards of quality \\
Assessment & $\begin{array}{l}\text { Serving the population is in the focus of this phase } \\
\text { to aim population health. Key elements are systematic } \\
\text { analysis and critical review using epidemiology and } \\
\text { evidence data. }\end{array}$ & $\begin{array}{l}\text { Recommendations on highly } \\
\text { complex technologies }\end{array}$ & $\begin{array}{l}\text { Responsiveness and maximization } \\
\text { of clinical outcomes and cost- } \\
\text { effectiveness }\end{array}$ \\
Management & $\begin{array}{l}\text { Health service providers are in the focus of this phase. } \\
\text { Key element is the operational management of } \\
\text { technology life-cycle using needs analysis and reliable } \\
\text { device availability for clinical use. }\end{array}$ & $\begin{array}{l}\text { Operational rules and guidance } \\
\text { for all medical devices }\end{array}$ & $\begin{array}{l}\text { Improved health delivery; sustainable } \\
\text { availability of high-quality and safe } \\
\text { devices }\end{array}$ \\
\end{tabular}

Source: Adapted from WHO (WHO, 2011a, WHO, 2011b)

context of the key findings, the findings of our previous studies and the results of our background research on current medical devices reforms and policies.

\section{Results}

The results of this study are structured along the areas regulation, assessment, and management and summarized by their importance in Table 4. Illustrative quotations are presented in Table 5.

\section{Area of regulation: Reporting of adverse events and complications during clinical practice}

There was some degree of consensus among interviewees that technovigilance activities (post-market surveillance of approved medical devices) should be strengthened across all levels of health-care delivery, but mainly at the meso level (health care institutions). Further, these activities may contribute to a wider scope of decision-making such as purchasing decisions. In

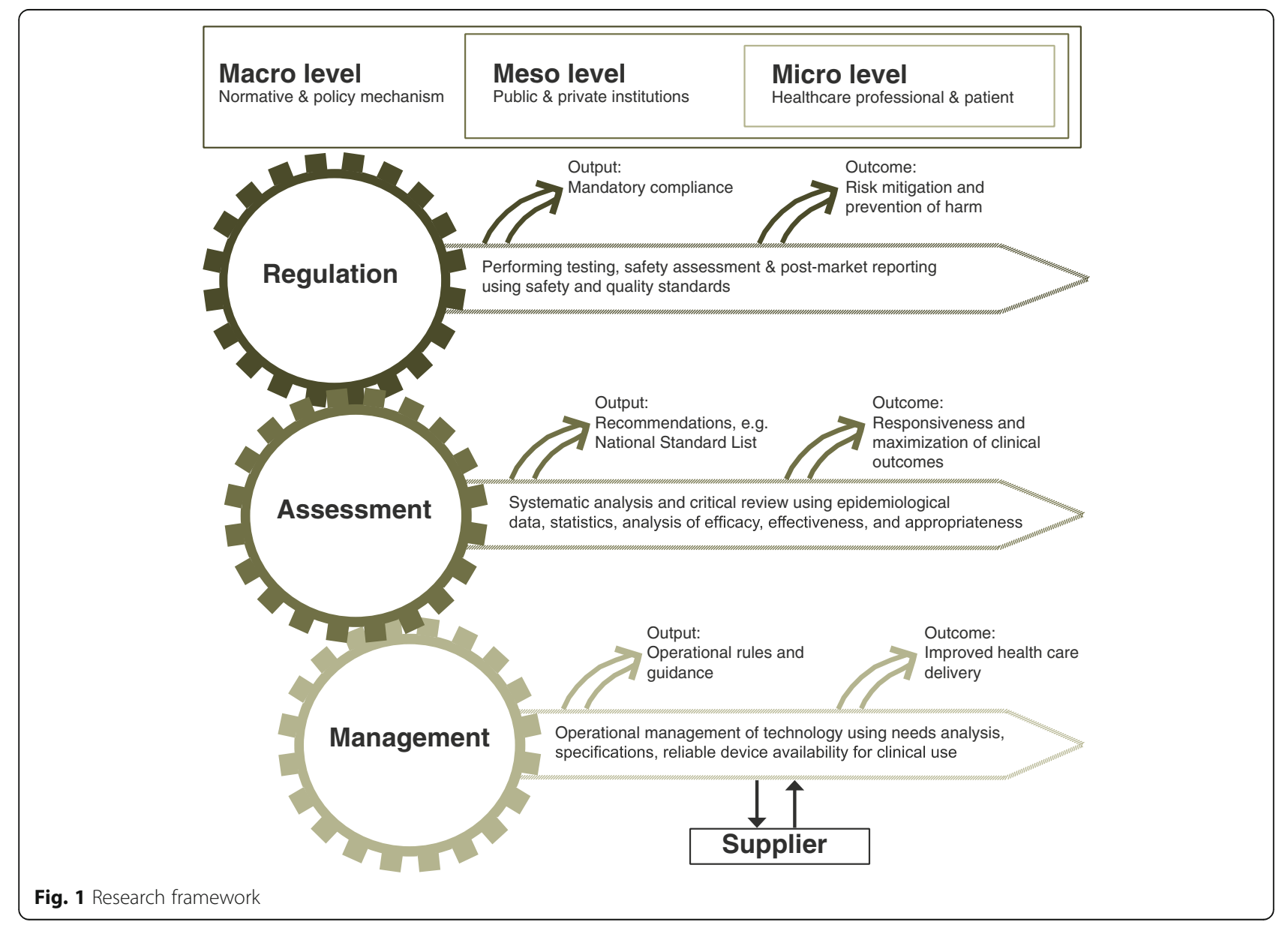


Table 3 Respondent characteristics

\begin{tabular}{|c|c|c|c|}
\hline \multirow[t]{2}{*}{ Stakeholder group } & \multirow{2}{*}{$\begin{array}{l}\text { Participant } \\
\text { N (\%) }\end{array}$} & \multirow{2}{*}{$\begin{array}{l}\text { Male } \\
\mathrm{N}(\%)\end{array}$} & \multirow{2}{*}{$\begin{array}{l}\text { Higher hierarchical leve } \\
\text { N (\%) }\end{array}$} \\
\hline & & & \\
\hline Group 1 (macro level) & $24(57)$ & $16(63)$ & $18(58)$ \\
\hline (i) Having direct relation to MDLC areas & $11(46)$ & $5(45)$ & $8(73)$ \\
\hline $\mathrm{CSG}, \mathrm{MoH}$, General directorates & $4(36)$ & $3(75)$ & $4(100)$ \\
\hline COFEPRIS, CENETEC & $6(55)$ & $2(33)$ & $3(50)$ \\
\hline $\begin{array}{l}\text { International organization or experts for } \\
\text { Mexican health system }\end{array}$ & $1(9)$ & $0(0)$ & $1(100)$ \\
\hline (ii) Indirect relation to $\mathrm{MDLC}$ areas & $13(54)$ & $11(85)$ & $10(77)$ \\
\hline MoH, General directorates & $3(23)$ & $2(67)$ & $2(67)$ \\
\hline $\begin{array}{l}\text { National institutes, organizations, or experts } \\
\text { concerned with public health, quality of } \\
\text { health services, or patient safety }\end{array}$ & $8(62)$ & $8(100)$ & $6(75)$ \\
\hline $\begin{array}{l}\text { International organization or experts for } \\
\text { Mexican health system }\end{array}$ & $2(15)$ & $1(50)$ & $2(100)$ \\
\hline Group 2 (meso level) $^{\mathrm{a}}$ & $5(12)$ & $2(40)$ & $4(80)$ \\
\hline Financing/provision of health services & $3(60)$ & $1(33)$ & $3(100)$ \\
\hline Quality of health services & $2(40)$ & $1(50)$ & $1(50)$ \\
\hline Group 3 (micro level) $^{\mathrm{a}}$ & $9(21)$ & $7(78)$ & $2(22)$ \\
\hline Orthopaedic specialists & $9(21)$ & $7(78)$ & $2(22)$ \\
\hline Group 4 (supplier) & $4(10)$ & $3(75)$ & $4(100)$ \\
\hline Medical device industry association & $1(25)$ & $0(0)$ & $1(100)$ \\
\hline Medical device supplier & $3(75)$ & $3(100)$ & $3(100)$ \\
\hline Total & $42(100)$ & $28(67)$ & $28(67)$ \\
\hline
\end{tabular}

${ }^{\mathrm{a} S o c i a l}$ security institutes and State-level health care systems

Mexico, monitoring activities for HRMD safety and performance take place under the supervision of the Technovigilance department of the Federal Commission for the Protection against Sanitary Risks, which relies on the reporting of health care institutions. Interviewees noted that the reporting of health care institutions is sub-optimal. The federal Technovigilance department encompasses decentralized departments of the SESA and the responsible technovigilance actors at the social security institutions. Few interviewees thought that they did not see significant advances in technovigilance activities since its introduction in 2013 and thought that it was not implemented sufficiently. They noted that technovigilance often only exists on paper rather than in daily practice. Interviewees provided different reasons for this. Many interviewees thought that monitoring the

Table 4 Frequency of discussed themes regarding challenges in organizational practice

\begin{tabular}{llllll}
\hline MDLC area & Total & Group 1 & Group 2 & Group 3 & Group 4 \\
\hline Regulation & $++(+)$ & $++(+)$ & $++(+)$ & ++ & $+(+)$ \\
Assessment & $++(+)$ & $++(+)$ & + & ++ & +++ \\
Management & $++(+)$ & ++ & ++ & +++ & +++ \\
\hline
\end{tabular}

+ low intensity; ++ some intensity; +++ high intensity safety and performance of HRMDs was insufficiently developed for a long time. Some interviewees from the macro level noted that a major difficulty to improve technovigilance was to coordinate the different subsystems of the Mexican health system. They stated that the commitment of users and suppliers to inform technovigilance officers about adverse events and incidents is irregular and activities at the meso level provide insufficient guidance to HRMD users.

Intra-operative complications are negative outcomes of using HRMDs during surgery and accompanying services such as instruments, implant sets, surgical technique, or technical assistance of supplier during surgery. Some interviewees stated that users report intraoperative complications to procurement administrators so that they can be managed in the context of service and delivery contract duties. But some noted as well that managing information about these complications is essential as these failures may influence medical outcomes in the long-term, considering their nature and frequency. Further, few interviewees noted that the awareness of the involved stakeholders about how reporting can contribute to decision-making at the meso and macro levels is low. Some interviewees thought that establishing an effective reporting system and infrastructure may 
Table 5 Quotations of interviewees

\begin{tabular}{|c|c|}
\hline Quotations & Stakeholder group \\
\hline \multicolumn{2}{|l|}{$\begin{array}{l}\text { Area of regulation: Reporting culture of adverse } \\
\text { events and complications during clinical practice }\end{array}$} \\
\hline $\begin{array}{l}\text { "Often they don't know that there is a regulation } \\
\text { for technovigilance." }\end{array}$ & Macro level \\
\hline $\begin{array}{l}\text { "... We explained to the health professionals that } \\
\text { finally they are the ones who complain about a } \\
\text { product that fails and that the product does not } \\
\text { provide the required results. However, me as } \\
\text { authority how can I take notice about that } \\
<\text { complaints }>\text { if they < end-users > dont make } \\
\text { notifications, if they don't report failures than I } \\
\text { cannot find it out and if I don't find it out I } \\
\text { cannot react, if I dont react the things stay as } \\
\text { they are." }\end{array}$ & Macro level \\
\hline $\begin{array}{l}\text { "... not only the bad quality of the materials but } \\
\text { also the bad service which they provide for } \\
\text { technical assistance... This type of complaint } \\
\text { converts into an internal report and stays there, } \\
\text { I am sorry that I have to say that." }\end{array}$ & Micro level \\
\hline $\begin{array}{l}\text { "... do you believe that the authorities of the } \\
\text { institutions don't know the needs that exist?" }\end{array}$ & Macro level \\
\hline \multicolumn{2}{|l|}{$\begin{array}{l}\text { Area of assessment: Decisions about the } \\
\text { eligibility of HRMDs }\end{array}$} \\
\hline $\begin{array}{l}\text { "... we noticed the extremely poor culture of } \\
\text { science that was present in the area of technology } \\
\text { assessment." }\end{array}$ & Macro level \\
\hline $\begin{array}{l}\text { "As a result of poor regulation every buys what he } \\
\text { wants and we complain about lots of things..." }\end{array}$ & Meso level \\
\hline $\begin{array}{l}\text { "A lot of people said as well that we should skip } \\
\text { the institutional standard lists." }\end{array}$ & Macro level \\
\hline \multicolumn{2}{|l|}{$\begin{array}{l}\text { Area of assessment: Decisions about the } \\
\text { eligibility of HRMDs }\end{array}$} \\
\hline $\begin{array}{l}\text { "I believe that the first error of the pseudo } \\
\text { transparency of implant procurement is that they } \\
\text { buy at the lowest price." }\end{array}$ & Macro level \\
\hline $\begin{array}{l}\text { "It's incredible that a surgery has to be cancelled } \\
\text { because the supplier did not arrive with the } \\
\text { material ... Which economic penalty can } \\
\text { compensate this damage to the patient..." }\end{array}$ & Micro level \\
\hline $\begin{array}{l}\text { "... a serious problem of the servicio integral is } \\
\text { that they decide which brands they include in } \\
\text { their service packages... Cheaper products so } \\
\text { that they make more profit." }\end{array}$ & Supplier \\
\hline $\begin{array}{l}\text { "... there are constant changes, when a new } \\
\text { person comes sometimes he dosent has sufficient } \\
\text { preparation to realize a tender." }\end{array}$ & Micro level \\
\hline $\begin{array}{l}\text { "... the procurement agent knows the standard } \\
\text { list but little about the basics of a joint implant." }\end{array}$ & Supplier \\
\hline
\end{tabular}

contribute to the strengthening of the evidence of intraoperative complications, which is contributing to technovigilance.

Area of assessment: Decisions about the eligibility of HRMDs Many interviewees indicated that the eligibility of orthopaedic HRMDs was not regulated thoroughly enough. Some interviewees noted that the current version of the standard list for orthopaedic and osteosynthesis medical devices still included several obsolete technologies or misleading descriptions. They noted that a major difficulty is that, by law, these changes to the standard list require formal modification requests from, e.g., a social security institution or a medical device supplier. Neither the inter-institutional committee nor the General Council of Health can implement such changes independently. Some interviewees thought that solving these problems of eligibility requires, among else, strong governance and improvement plans. They noted that updating the standard list is important, but only as a prerequisite rather than as a sustainable step in improving the post-market regulation of HRMD eligibility. Despite the national standard list (macro level), each public health institution manages its own standard list for health supplies (meso level). Few interviewees thought that it was necessary to unify these standard lists into one single standard list.

\section{Area of management: Procurement decision-making, purchasing strategy, procurement agent competencies}

In Mexico, decision-making is strongly guided by conformity checks of HRMD specifications (e.g. material, mechanical characteristics, dimensions) and lowest-price offers [3-5]. Many interviewees thought that the applied procurement regulations and practices in use have not advanced over the past years. Some interviewees noted that decision makers had difficulties understanding differences between medical device brands in terms of their clinical performances (e.g. implant survival rate, primary stability of implant, implantation based on surgical technique). They thought that improved and systematic risk assessment of HRMDs might elucidate risks in a wider scope with the potential to lead to a more thorough use of public budgets, such as Health Technology Assessments (HTA) at hospital level. They noted that medical devices are currently not assessed sufficiently such as implant survival rate. Some interviewees thought that integrating aspects of quality more thoroughly could contribute to the changing of decision-making criteria.

Some interviewees thought that solving deficiencies of specific purchasing strategies could positively influence procurement outcomes and the quality of services provided, respectively. They noted that nowadays outcomes are affected by sub-optimal supplier performance; suppliers are often unable to respond timely with material and technical support to contract assignments because they are often contracted shortly before the contract period started. Many interviewees noted that the increasing use of the bundling of services through Servicios integrales requires more quality control. A Servicio integral encompasses a range of disposable and nondisposable medical products used for surgery and merges them into one supplier service. Some interviewees noted 
that this facilitates the public sectors' administrative processes, but it also removes the procurement administrators' control of the final selection of the orthopaedic HRMD brand.

Some interviewees explained that decision makers underestimated the role played by the procurement agent who is concerned with administrative tasks and processes to support needs assessment or analysing supplier offers. They thought that procurement agents should have minimal professional skills underlined by specific certificates so that they were able to understand clinical needs better and to not affect negatively procurement results. Many noted that administrators often have difficulty understanding the clinical needs of users and underestimate the consequences of their decisions about clinical procedures. Some of the interviewees mentioned the importance of continuous training; it could contribute to changing a purely administrative passive support into a more integrated service function. Until now, little attention has been paid to the continuous education of procurement agents.

\section{Discussion}

Interview participants identified important challenges in relation with the MDLC areas in Mexico (affecting policy outputs and outcomes), which might influence the quality of care. With regard to regulation, reporting of adverse events was perceived as the most important challenge; assessment is challenged by several obsolete or wrongly described technologies in the standard list for orthopaedic and osteosynthesis products; while integrating advanced quality attributes into procurement processes was a mayor issue raised regarding the area of management. According to interviewees, subjacent to these challenges is the fragmentation of responsibilities with regard to the MDLC areas and the disconnection of the several sub-systems of health care. Overall we found that this causes a lack to support well-integrated MDLC areas and translates into sub-standard outputs and outcomes. In consequence the multiple actors have difficulties to improve the quality of delivered health care. Possible ways forward in fostering the regulation, assessment, and management of medical devices in Mexico are:

- Regulation: Strengthening technovigilance

- Assessment: Updating the Standard list for orthopaedic and ostheosynthesis medical devices

- Management: Introducing a decision-making guidance with focus on quality attributes for decision-making, purchasing strategy, and procurement agent competencies
We found that strengthening technovigilance can potentially improve outputs and outcomes of the regulation in the following ways: It can influence the compliance of involved stakeholders (e.g. for post-market reporting) and contribute to improved quality. To strengthen technovigilance three aspects may be considered: (i) including technovigilance tasks in the requirement catalogue of hospital certifications, (ii) fostering inter-institutional technovigilance guidelines, and (iii) implementing a technovigilance code of conduct (for hospital providers, health-care workers and suppliers). Further, in the literature we found that countries having a well-functioning post-market surveillance system complement their regulatory tasks by integrating specific approaches into the regulators' work to evaluate health technologies or define benchmarks for quality standards $[16,17]$.

We found that introducing a guidance focusing on quality attributes can improve outputs and outcomes of the assessment and management in the following ways: It can enrich decision-making by knowledge about clinical longterm performance of medical devices, and improve clinical outcomes and cost-effectiveness. Further, it can influence operational rules and guidance for orthopaedic HRMDs and contribute to improved quality of delivered of health care. To introduce stronger quality attributes the following aspects may be considered: (i) introducing quality benchmarks for orthopaedic procedures (e.g. survival rate requirements) and establishing survival rate expectations for new listed technologies; and (ii) Introducing HTA at the level of hospitals or purchasing groups that allow to integrate a risk assessment of orthopaedic HRMDs into decision-making. Further, we found that in the United Kingdom the National Institute for Health and Care Excellence defines recommendations including benchmarks, e.g., for the quality of hip prostheses, as "the new joint should work well in at least $95 \%$ of hip replacements over 10 years, instead of the current 90\%" [18]. These recommendations contribute to the maximization of clinical outcomes and costeffectiveness and can be reflected in risk assessments for orthopaedic HRMDs [19, 20]. Understanding the role played by decision makers concerning the absence of high-quality data is an important insight into procurement activities such as purchase and supply [21,22].

We found that enhancing competencies of procurement agents can improve outputs and outcomes of the management phase in the following ways: It can influence operational rules and guidance for orthopaedic HRMDs and contribute to improved health care delivery. To enhance competencies of procurement agents the following aspects may be considered: (i) Updating requirements for core competencies needed for procurement agents, and (ii) integrating procurement agents into evaluation tasks of outcomes of applied purchasing 
strategies such as Integral Services. Further, in other countries the orthopaedic specialist still has high decision-making autonomy, which alleviates some responsibility from the procurement agent. Thus we had difficulties to find examples emphasizing the aspect of enhancing competencies of procurement agents.

This study highlights important findings in a national context. However, some issues identified by the present study do emerge in a similar way in other health systems as well. For instance, the Swiss healthcare system is characterized by a decentralized structure with large decision-spaces at cantonal (regional) level. However, the healthcare legislative allows for initiatives and programmes that benefit the whole of the country so that the fragmentation of responsibilities regarding the MDLC areas is contained. For instance, Switzerland did face similar problems as Mexico relating to post-market surveillance regarding the level of clinical long-term data available for orthopaedic medical devices. As a solution to this a national arthroplasty registry, which is overseen by the National Association for Quality in healthcare facilities, was introduced. This was only possible by substantial commitment of the different parties concerned by the registry such as national and local policy makers, insurances, the associations of orthopaedic surgeons and the medical device industry. The Mexican healthcare system is characterized by various sub-systems of health service provision. The healthcare legislative limits the authority of the $\mathrm{MoH}$ to establish initiatives or programmes regarding medical devices that could benefit the whole sector. For instance, the social security institutes apply their own regulations for the assessment and management of medical devices. We found that this fragmentation of responsibilities influences the ability of policy makers to carry forward promising ways to improve outputs and outcomes of the MDLC areas. However, the relation between the $\mathrm{MoH}$ and sub-systems is in a transition and some recent advances demonstrate that [12, 23, 24]. For instance, policy makers agreed on an information technology system that enables them to consolidate relevant key data across the different sub-systems at federal level. This system that is supported by all sub-systems is called the National System of Basic Information in Healthcare (SINBA) [26]. It is under the supervision of the National Department for Information in Health of the Ministry of Health and can significantly contribute to improvement. SINBA is still in progress but expected to be launched by end of 2017. It represents an information strategy for capturing and consolidating data across the different sub-systems. As next steps for the policy making process in Mexico we recommend to take into account that the integration of stakeholders such as the National Academy for Medicine, the associations of orthopaedic specialists, and the associations of the medical device industry is important as they can contribute to the establishment of initiatives and programmes to improve the MDLC areas, and help to partially overcome the fragmentation of responsibilities. An important next step is the strengthening of Technovigilance.

\section{Limitations of the study}

For this study, we used non-random sampling, which does not necessarily guarantee the sample being representative for the population of person involved in the regulation, assessment, and management of medical devices in Mexico. However, this study includes 42 stakeholders working in the field of regulation, assessment, management or clinical practice. Thus it covers different groups of stakeholders in terms of expertise. We were not granted permission to include employees of the Mexican Institute of Social Security, which is the largest social security institution in Mexico, because of its research study approval policies. Further, the sampling is based on a maximum variation strategy and may constitute a selection bias. The interpretation of the findings that served to define possible ways forward to fostering the regulation, assessment, and management of orthopaedic medical devices is a subjective process.

\section{Conclusions}

This study provides a broad analysis of medical device functions within a health system and highlights in this specific context how improvements might be achieved. It addresses a broad range of interest groups represented by policy makers, health service providers, managers and administrators of healthcare facilities, and doctors with an interest in health technologies. In this paper we highlight important themes that influence outputs and outcomes of the regulation, assessment, and management and discuss strategies in fostering these areas. To date, the regulation, assessment, and management of medical devices are rarely analysed in a broad way, even though these functions importantly contribute to the successful implementation of health technology policies. The quality of delivered healthcare is influenced by the performance between and within these functions. In Mexico, little discussion has been raised on challenges of the regulation, assessment, and management of medical devices. Changes to current processes and practices can improve outputs and outcomes of these functions and positively influence the quality of delivered healthcare. Stakeholder involvement and commitment is essential to this.

To overcome the impact of the fragmentation in the Mexican health system, policy makers could orientate on what other countries with a similar complex health sector are doing to improve outputs and outcomes of the MDLC such as the United States, Germany, or Switzerland. An important advance is that the Ministry of Health is developing a new policy that targets to strengthen 
technovigilance across all sub-systems. This is a promising way forward in fostering the regulation and to fully engage all stakeholders. This study may contribute to show to policy makers additional ways forward in fostering the regulation, assessment, and management towards improved quality of delivered health care.

\section{Additional file}

Additional file 1: Interview Guide. (DOCX $117 \mathrm{~kb}$ )

\section{Abbreviations}

CENETEC: Centro Nacional de Excelencia Tecnológica en Salud (National Centre for Health Technology Excellence); COFEPRIS: Comisión Federal para la Protección contra Riesgos Sanitarios (Federal department of health and human services of Mexico); CSG: Consejo de Salubridad General (General Council of Health); DGCE: Dirección General de Calidad y Educación (General directorate of quality and education); DGPD: Dirección General de Planeación y Desarrollo (General directorate of health planning and development); HRMD: High-risk medical device; HTA: Health Technology Assessment; MDLC: Medical Device Life-Cycle; SESA: Servicios Estatales de Salud (State-level health care systems); SIDSS: Subsecretaría de Integración y Desarrollo del Sector Salud (Sub-secretariat for Health System Integration and Development); WHO: World Health Organization

\section{Acknowledgements}

We are particularly grateful to the many people who participated in this study, since, without their involvement this investigation would not have been possible procedures, and to provide a proposal plan how to improve procurement outcomes.

\section{Funding}

The authors declare that they do not have an external funding source. The corresponding author and the co-authors have not received any monetary support to realise this specific research.

\section{Availability of data and materials}

The data supporting our findings is contained within the manuscript and within Table 5. The original transcripts of all interviews will not be shared due to confidentiality reasons.

\section{Authors' contributions}

All authors were involved in the outline of the paper. ML has made substantial contributions to conception and design, acquisition of data, analysis and interpretation of data, and drafting the manuscript. AD, KW and LD have been involved in revising the manuscript critically for important intellectual content and structure, and have given final approval of the version to be published.

\section{Competing interest}

The authors declare that they do not have conflicts of interest.

\section{Consent for publication}

Not applicable.

\section{Ethics approval and consent to participate}

The ethical committee of the Autonomous University of Mexico [23] approved this project (Date of approval: November $4^{\text {th }} 2014$, FMED/CI/SPLR/ 188/2014), and the Ethical committee from northwest and central Switzerland (Switzerland) exempted it from ethical review under Swiss law (June $24^{\text {th }} 2014$ ). All interviewees gave written informed consent before the interview.

\section{Publisher's Note}

Springer Nature remains neutral with regard to jurisdictional claims in published maps and institutional affiliations.

\section{Author details}

${ }^{1}$ Swiss Tropical and Public Health Institute, Swiss Centre for International Health, Socinstrasse, 574051 Basel, Switzerland. 'University of Basel,
Petersplatz 1, 4003 Basel, Switzerland. ${ }^{3}$ National Institute of Public Health, Universidad No. 655 Colonia Santa María Ahuacatitlán, Cerrada Los Pinos y Caminera C.P., Cuernavaca 62100, Morelos, Mexico. ${ }^{4}$ National Centre for Children and Adolescence Health, Francisco de P. Miranda 177, 1st floor, Álvaro Obregón, Lomas de Plateros, C.P., 01480 Mexico City, Mexico.

Received: 7 February 2017 Accepted: 5 March 2017

Published online: 14 March 2017

\section{References}

1. WHO. World Health Organization. WHO Library Cataloguing-in-Publication Data. Development of medical device policies (WHO Medical device technical series). http://www.who.int/medical_devices/policies. Accessed 02 Aug 2016. 2011

2. WHO. World Health Organization. Country data - Global atlas of medical devices 2014 update. http://www.who.int/medical_devices/countries/mex. pdf?ua=1. Accessed 15 Aug 2016. 2014

3. Lingg M, Wyss K, Duran-Arenas L. How does the knowledge environment shape procurement practices for orthopaedic medical devices in Mexico? BMC Med Inform Decis Mak. 2016;16(1):85. doi:10. 1186/s12911-016-0324-1.

4. $\quad$ Lingg M, Wyss K, Durán-Arenas L. Effects of procurement practices on quality of medical device or service received: a qualitative study comparing countries. BMC Health Serv Res. 2016;16(1):1-13. doi:10.1186/s12913-016-1610-4.

5. Lingg M, Merida-Herrera E, Wyss K, Durán-Arenas L. Attitudes of orthopaedic specialists towards effects of medical device purchasing. Int J Technol Asses Health Care. 2017;Accepted for publication: 19 Jan 2017.

6. Duran-Arenas L, Salinas-Escudero G, Granados-Garcia V, Martinez-Valverde S. Transforming health systems based on primary care. Gac Med Mex. 2012; 148(6):552-7.

7. Puig A, Pagan JA, Wong R. Assessing quality across healthcare subsystems in Mexico. J Ambul Care Manage. 2009;32(2):123-31. doi:10.1097/JAC. 0b013e31819942e5.

8. FDA. U.S. Food and Drug Administration. Classify your medical device. http://www.fda.gov/MedicalDevices/DeviceRegulationandGuidance/ Overview/ClassifyYourDevice/default.htm. Accessed 19 Jan 2017. 2017.

9. Gómez-Dantés O, Sesma S, Becerril V, Knaul FM, Arreola H, Frenk J. The health system of Mexico. Salud Publica Mex. 2011;53(2):220-32.

10. PAHO. Organización Panamericana de la Salud. Perfil del sistema de servicios de salud México. http://www1.paho.org/hq/dmdocuments/2010/ Perfil_Sistema_Salud-Mexico_2002.pdf. Accessed 21 Oct 2016. 2002.

11. Frenk J, González-Pier E, Gómez-Dantés O, Lezana MÁ, Knaul FM. Reforma integral para mejorar el desempeño del sistema de salud en México. Salud Publica Mex. 2007;49:523-36.

12. OECD. OECD Reviews of Health Systems: Mexico 2016. Paris: OECD Publishing; 2016.

13. Mayring P. Qualitative Inhaltsanalyse. Grundlagen und Techniken. Vol. 12. Beltz publishing; 2015

14. Council Directive 93/42/EEC. Medical Device. http://eur-lex.europa.eu/ LexUriServ/LexUriServ.do?uri=CONSLEG:1993L0042:20071011:en:PDF. Accessed 7 Feb 2017. 1993.

15. Schreier M. Qualitative Content Analysis in Practice. SAGE Publications; 2012

16. Wilkinson J, Crosbie A. A UK medical devices regulator's perspective on registries. Biomedizinische Technik Biomedical engineering. 2016;61(2):2337. doi:10.1515/bmt-2015-0142.

17. Randall H. Early experience of the European Medical Devices Vigilance System. Australas Phys Eng Sci Med. 1997;20(4):203-6.

18. NICE. National Institute for Health and Care Excellence. Updated NICE guidance on hip replacement and resurfacing recommends more durable artifical joints. https://www.nice.org.uk/news/press-and-media/updated-niceguidance-on-hip-replacement-and-resurfacing-recommends-more-durableartificial-joints. Accessed 20 Jul 2016. 2014.

19. ODEP. Orthopaedic Data Evaluation Panel. http://www.odep.org.uk. Accessed 17 Aug 2015. 2015

20. Poolman RW, Verhaar JA, Schreurs BW, Bom LP, Nelissen RG, Koot HW, et al. Finding the right hip implant for patient and surgeon: the Dutch strategyempowering patients. Hip Int. 2015;25(2):131-7. doi:10.5301/hipint.5000209.

21. Lansky D, Milstein A. Quality measurement in orthopaedics: the purchasers' view. Clin Orthop Relat Res. 2009:467(10):2548-55. doi:10.1007/s11999-0090999-z. 
22. Smith N, Mitton C, Davidson A, Williams I. A politics of priority setting: Ideas, interests and institutions in healthcare resource allocation. Public Policy and Administration. 2014;29(4):331-47. doi:10.1177/0952076714529141.

23. Mexico Health Review. http://www.mexicohealthreview.com. Accessed 12 Feb 2017. 2016.

24. PWC. PricewaterhouseCoopers. 2015 Health Services Perspectives in Mexico. https:/www.pwc.com/mx/es/industrias/archivo/2014-12-health-sectorperspectives-mexico-2015.pdf. Accessed 03 Jun 2016. 2015.

Submit your next manuscript to BioMed Central and we will help you at every step:

- We accept pre-submission inquiries

- Our selector tool helps you to find the most relevant journal

- We provide round the clock customer support

- Convenient online submission

- Thorough peer review

- Inclusion in PubMed and all major indexing services

- Maximum visibility for your research

Submit your manuscript at www.biomedcentral.com/submit 